\title{
SURVEY ON THE PRESENT STATUS OF INFRASTRUCTURE AND QUALITY MANAGEMENT SYSTEM IN GOLDA FARMS AND DEPOTS OF SELECTED AREA
}

\author{
M. N. Haider, M. Faridullah, M. N. Islam and M. Kamal \\ Department of Fisheries Technology, Bangladesh Agricultural University \\ Mymensingh-2202, Bangladesh
}

\begin{abstract}
Post harvest qualitative and quantitative changes have been studied in an important crustacean species prawn, Golda (Macrobrachium rosenbergii) of Bangladesh at various stages of handling Golda have been studied. Detailed information on post-harvest handling, storage, transportation, and distribution of prawn using pre-tested questionnaires was collected from some selected farms and depots of four Golda producing districts viz. Khulna, Bagerhat, Jessore and Norail area. The information on various aspects was collected through interview with cross section of people engaged in farms and depots. The aspects of information collected on Golda farms were: farm conditions, infrastructure, harvesting, farm production, post-harvest care, transportation and quality measures. Information collected on various aspects of depots was: infrastructure facilities, condition of shrimp during receiving, handling, transportation, washing and owners' opinion about the quality of prawn from previous year experiences. The post-harvest losses of Golda is due to soft shell, improper washing or washing with unclean water, longer duration of harvesting, exposure of shrimp at high ambient temperature for a long time (delayed icing), contamination, piled up on a dirty floor, general lack of hygiene and dipping in water to weight gain was about $1-4 \%$ of the total harvested quantity.
\end{abstract}

Key words : Golda farm, Depots, Infrastructure, Quality management

\section{INTRODUCTION}

Freshwater prawn, Golda (Macrobrachium rosenbergii) is classified as a luxury item, competing with other crustacea. Prawns and shrimps are considered as the most important aquaculture products of Bangladesh (Rahman et al., 2001a). Golda is the largest one among the freshwater prawns and the consumer at home and abroad prefer Golda for its taste, size and color. Bangladesh is a major exporter of $M$. rosenbergii caught in rivers, lakes and flooded depressions (Angell, 1992). In the early 1990s, the vast majority of more than $90 \%$ of the freshwater prawns exported from Bangladesh derived from natural resources, with an estimated 60\% deriving from the Khulna- Bagerhat area, 35\% from Commilla and Noakhali districts and only 5\% from Cox's Bazar area (DIFTA, 1993). However, with the increasing demand in the international market, Golda farming has been expanding rapidly throughout the country, particularly in Jessore, Norail, 
Jenaidaha, Khulna, Bagerhut, Satkhira, Commilla, Chandpur, Mymensingh and Kishoregong area.

Over the recent years, there has been a notable increase in the export prices of the Bangladeshi prawn particularly in USA, Japan, and European markets (Ahmed, 2001). Although, Bangladesh developed very impressive shrimp and fish processing and freezing plants over the last 15 to 20 years from only 9 (1971) to 129 (2005) but in 1997 EC countries put embargo on Bangladeshi shrimps import due to quality problems. Under these circumstances some processing industry owners have upgraded their industries with modern technologies and facilities. Later this embargo has been lifted and presently $57 \mathrm{EU}$ approved processing plants are in the country to produce and export good quality shrimp and prawn products (DoF, 2005). Considerable amount of quality degradation occur at farm and supply chain due to improper infrastructure and quality management facilities. The study was conducted to know the status of infrastructure facilities, assess the level of quality degradation and estimate quantitative losses of prawn at various stages of handling from farms to supply of processing plants and to determine the causes of such losses.

\section{MATERIALS AND METHODS}

Information on the present status of infrastructure facilities and quality management system of Golda farms and depots of Khulna, Bagerhat, Jessore and Norail districts were collected using pre-tested questionnaires and through interviews. From each district 2 upazilas and from each upazila 2 farms and 2 depots were selected i.e. a total number of 16 Golda farms 16 depots were selected randomly representing the maximum Golda farming of selected districts. The questionnaires were developed jointly by the Department of Fisheries Technology, Bangladesh Agricultural University, Mymensingh and Bangladesh Shrimp Foundation, Dhaka.

\section{RESULTS AND DISCUSSIONS}

The data about the present status of infrastructures, harvesting, handling and transportation were collected from the farm and depot owners of four Golda districts of Khulna, Bagerhat, Jessore and Norail. The results obtained from Golda farms are summarized and presented in Table 1 to 9 .

\section{Overall conditions of the Golda farms}

All the Golda farms surveyed in four districts of Bangladesh usually practiced the similar management system. It is found that about $70 \%$ farms received and drain out water to another pond in all survey areas. Almost all the farms use little or no organic manure like cow-dung or chicken waste in the ponds. Although, no latrine was found to be constructed on the Golda farms, there is a chance of contamination of the water with sewage through the water receiving canal from other sources. Removal of the pond scum is not a familiar practice in any of the ponds. Generally, in the Golda farms both rain and 
river water was found to use as main sources of water. The average depth of the Golda farms was like the pond used for poly-culture of fin-fishes with a range of 3 to 4 feet. The mortality rate in the farms is relatively lower which is about $5-10 \%$ mainly as a result of poor water quality and disease out break. There is no practice of the regular monitoring of the water quality (Table 1).

Table 1. Overall conditions of the Golda Farms of Bangladesh

\begin{tabular}{lc}
\hline \multicolumn{1}{c|}{ Major Aspects } & Golda farms \\
\hline 1. Water received or drain out to another farm & $70 \%$ farms receive or drain out to other farms \\
2. Latrine on the farms & No \\
3. Removal of pond scum & No \\
4. Water source & Rain and river water \\
5. Water quality monitoring & No \\
a) pH & $3-4 \mathrm{ft}$ \\
b) Depth & No \\
c) Secchi disc reading & $5-10 \%$ due to disease and poor water quality \\
d) Mortality
\end{tabular}

\section{Infrastructure facilities to the Golda farms}

Most of the Golda farmers were found to be less concerned about the infrastructure development. Only about $10 \%$ farms built shade for keeping the harvested prawn. An appreciable matter is that there is no use of bamboo basket in the farms rather they use plastic sheet, plastic drum and cemented floor for temporary holding of the harvested prawn. But for transportation of harvested prawns from farms to the depots or receiving centers, about $80 \%$ bamboo made and $20 \%$ plastic containers were used. There was no ice storage facility and ice crushing box in the Golda farms which is essential to keep the freshness for longer periods (Table-2).

Table 2. Infrastructure facilities of Golda farms

\begin{tabular}{lc}
\hline \multicolumn{1}{c|}{ Major Aspects } & Golda \\
\hline $\begin{array}{l}\text { 1. Shade for keeping the harvested shrimp } \\
\text { 2. Temporary holding of shrimp }\end{array}$ & $10 \%$ farms built shade \\
& $70 \%$ Plastic sheet, $20 \%$ plastic drum and $10 \%$ \\
3. Basket type & cemented floor \\
4. Ice storage facilities & No bamboo, 20\% plastic \\
5. Ice crushing box & No \\
\hline
\end{tabular}

\section{Production and harvesting methods of Golda}

Here, production, harvesting, sanitation, quality aspects and worker's hygiene of the Golda farms are discussed. Golda are harvested mostly at daytime (Table-3). Cast net is 
the major gear used in all the farms. It usually takes 3-6 hrs for the marketing of the harvested Golda. The production of prawns ( $\mathrm{kg} / \mathrm{acre})$ in addition to other shellfish and finfish were as follows: Golda-200-400, horina 10-20, and finfish 50-100. Usually Golda farms do not produce bagda but some farms in Bagerhat are reported to produce bagda of about $50-100 \mathrm{~kg} /$ acre. It is to be noted that most (about $80 \%$ ) of the workers of the Golda farms have little or no knowledge about prawn quality, personal hygiene and sanitation, but about $90 \%$ of the harvested Golda are found in excellent condition. About $1-4 \%$ of the harvested Golda had soft shell.

Table 3. Production and harvesting methods of Golda at farms

\begin{tabular}{lc}
\hline \multicolumn{1}{c}{ Major Aspects } & Golda \\
\hline 1. Harvesting time & $90 \%$ day time, $10 \%$ at night in low tide \\
2. Harvesting method & $100 \%$ cast net \\
3. Duration between start of harvesting to marketing & $3-6$ hrs \\
4. Farm production (kg/acre) & Golda-200-400, Horina-10-20, Finfish-50-100 \\
5. Knowledge of workers about shrimp quality & $80 \%$ poor, 20\% fair \\
6. Quality of harvested shrimp & $90 \%$ excellent, 6-8\% fair \\
7. \% soft shell & $1-4 \%$ \\
\hline
\end{tabular}

\section{Post harvest handling and transportation of Golda}

Table- 4 shows the post harvest care and transportation of Golda at farm levels. In the Golda farms both pond water and tube-well water is used for initial washing of harvested Golda. Generally sorting and grading are not practiced but some farms in Avoynagar under Jessore district used to grade Golda before transporting to the depot. The farmers usually do not remove head at farm level with the exception of some farms of Avoynagar area where the farmers sometimes remove head before selling it to buyers. Ice is not generally used at farm level but some farms of Bagerhat area reported that they use ice regularly after harvest. The baskets and mats used at the Golda farms are washed regularly normally with the pond water but in most cases they do not use any type of detergent for washing. The harvested Golda is transported to the depots and the distance from farm to depots is 1-6 km. For the transportation of harvested prawn from the farm house to the depots both bamboo baskets and plastic baskets are used. Rickshaw is the most commonly used transport $(70 \%)$ while van is also used $(10 \%)$ in some cases and the remaining $20 \%$ are transported by carrying on head to the nearly depots.

\section{Major infrastructure facilities of Golda depots}

Results of the investigation on infrastructure facilities of Golda depots are cited in Table5. Major infrastructure facilities that are considered for evaluation are- building (roof, ceiling, walls, floors, windows, doors etc) stainless steel table, animal control fencing, ice plant, ice storage, sanitary latrine, drainage, electricity, water source and foot dip. None of the depot building is well constructed. About $80 \%$ roofs of the depots are found to be tin made while $20 \%$ are made of concrete. However, no depot was found to use straw for 
roof building. But in case of ceiling the overall situation is not satisfactory. About $80 \%$ Golda depots have no ceiling and remaining $20 \%$ has straw or bamboo made ceiling. The walls of the depots are mainly made of bricks $(87 \%)$ and $13 \%$ with tin. The floors of all the Golda depots are cemented with only $2 \%$ mosaic floor. None of the depots have screen or nets in the doors and windows to prevent flies and insects (Table-5).

Table 4. Post harvest handling and transportation at Golda farms

\begin{tabular}{lc}
\hline \multicolumn{1}{c}{ Major Aspects } & Treatment of Harvested Golda \\
\hline 1. Initial washing after harvest & $50 \%$ pond water, $50 \%$ tube well water \\
2. Sorting and grading & $90 \%$ cases no sorting and grading \\
3. Shrimp head removal & $90 \%$ do not remove, $10 \%$ remove head \\
4. Ice used & $95 \%$ do not use ice, $5 \%$ farmers use ice \\
5. Basket washing & $100 \%$ washed regularly \\
6. Mat washing & $100 \%$ washed regularly \\
7. Detergent used & No \\
8. Distance from farm to depot $(\mathrm{km})$ & $1-6$ \\
9. Transportation container & $50 \%$ bamboo, $50 \%$ plastic drum \\
10. Transportation from farm to depot & $70 \%$ rickshaw, $10 \%$ van \\
\hline
\end{tabular}

About 77\% Golda depots have stainless steel table for sorting of raw materials but in most cases they are not in suitable condition or in use. About $90 \%$ of the depots have no fencing to control large mammals and animals. Although, there is no ice plant of their own the depots of the study area has ice storage facilities in all cases. Ice is usually collected from nearby markets or towns. Only 10\% depots was found to have latrine but $90 \%$ had no sanitary latrine. The drainage system of the depots is inadequate and in very poor condition. Electricity is available in all the depots. Tube well water is the main source of water. None of the depots have foot dip facility in the study area.

\section{Receiving criteria of Golda at depots}

The major criteria used for receiving prawn at the depots included are transport container, icing, head removal, grading, transport, distance between farms and depots, total quantity of prawn collected (last year), total quantity of ice used (last year), and cost of ice (Table-6). For transportation both bamboo basket and plastic baskets are used. About $90 \%$ raw materials are received by the depots with no-iced condition which is a deciding factor for quantitative as well as qualitative losses. The Golda arrived in the depots with head-on condition and about $63 \%$ of them were in non-graded condition. About $80 \%$ prawns are transported to the depots using rickshaw while rickshaw-van are used for remaining $20 \%$. According to the depot owners the distance between Golda farms and depots are in the range of $1-10 \mathrm{Km}$. Average amount of prawn received last year was reported to be in the range of 10-25 mt. by an individual Golda depot. The quantity of ice used for icing of Golda by an individual depot was reported to be in the 
range of 1-20 tons last year. Depending on the season, demand and availability the price of ice was found to vary from TK.1.20-2.00/ $\mathrm{kg}$ (Table-6).

Table 5. Major infrastructure facilities of Golda depots

\begin{tabular}{lc}
\hline \multicolumn{1}{c}{ Major Aspects } & Observation \\
\hline 1. Roof & $80 \%$ tin, $20 \%$ concrete \\
2. Ceiling & $80 \%$ no ceiling, $20 \%$ bamboo or straw \\
3. Walls & $87 \%$ bricks, $13 \%$ tin \\
4. Floor & $98 \%$ cemented , $\%$ mosaic \\
5. Windows & $100 \%$ no net \\
6. Doors & $100 \%$ no net \\
7. Stainless steel table & No \\
8. Animal control fencing & Yes \\
9. Ice plant & $90 \%$ has no fencing \\
10. Ice storage & Yes \\
11. Sanitary latrine & Yes \\
12. Drainage & Tube well \\
13. Electricity & $90 \%$ has no sanitary latrine, $10 \%$ has latrine \\
14. Water source & $100 \%$ depot has no foot dip \\
15. Foot dip &
\end{tabular}

Table 6. Receiving criteria of Golda at depot

\begin{tabular}{lc}
\hline \multicolumn{1}{c|}{ Major Aspects } & Observation \\
\hline 1. Container type & $50 \%$ Bamboo basket, $50 \%$ plastic drum \\
2. Icing & $90 \%$ not in iced condition, $10 \%$ iced condition \\
3. Head & Head on \\
4. Grading & $67 \%$ non graded, $37 \%$ graded \\
5. Transport & $80 \%$ rickshaw, $20 \%$ van \\
6. Distance between farm and depot & $1-10 \mathrm{~km}$ \\
7. Total quantity (last year) & $1-20$ tons \\
8. Ice quantity(last year) & $1-25$ tons \\
9. Ice cost & Tk. $1.20-2.00 / \mathrm{kg}$ \\
\hline
\end{tabular}

\section{Handling at depots and transportation to the factory}

After receiving the prawn at depots some important activities are performed and then transported to the factory (Table 7). The major aspects that are considered here are- head removal, peeling, size grading washing, icing, packaging, container, maximum holding time, distance from factory, time to reach at factory, waiting time for delivery etc. 
From the collected information it was found that about $50 \%$ of the collected prawns were transported to the factory with head-on condition and remaining 50\% headed at the depots and then transported to the processing plants. But in both cases it is reported that the prawns are not peeled at depots. In all the depots grading before transportation to the factory is a common practice. Generally the collected Golda are washed with tube well water and preserved in ice at an ice-prawn ratio of 1:1. After that the graded Golda are packed in either bamboo or plastic baskets and polythene sheet to transport to the processing industry. Usually, the maximum holding time of Golda at depots ranges from 2-12 hrs. Both plastic and bamboo made containers are used for transportation and in $75 \%$ cases plastic containers are used. It has been reported that the distance of the processing industry from the depots is in the range of $9-40 \mathrm{~km}$. It usually takes $1 / 2-4 \mathrm{hrs}$ to reach the collected prawns to the factory. It has also been reported that, the waiting time for delivery of the prawns to the factory is 1- $20 \mathrm{hrs}$. They usually use lifebuoy soap, bleaching powder, detol or savlon antiseptic for the washing of floor, basket, mat and weighing machine in the Golda depots (Table-7).

Table 7. Handling at depots and transportation of Golda to the factory

\begin{tabular}{lcc}
\hline \multicolumn{1}{c}{ Major Aspects } & Observation \\
\hline 1. Head removal & No \\
2. Peeling & Yes \\
3. Size grading & Yes \\
4. Washing & Use ice in the ratio of $1: 1$ \\
5. Icing and ice ratio & Bamboo and plastic \\
6. Packaging & $2-12$ \\
7. Max. holding hour & $75 \%$ plastic, $25 \%$ bamboo not remove head \\
8. Container & $9-40 \mathrm{~km}$ \\
9. Distance from factory & $0.5-4 \mathrm{hrs}$ \\
10. Time to reach at factory & $3-10 \mathrm{hrs}$ \\
11. Waiting time for delivery &
\end{tabular}

\section{Depot owners' opinion about the quality of Golda}

Table 8 showing the opinions of the depot owners about overall quality and quality defects. According to depot owners, less than 1\% Golda received from suppliers/farmers were found as spongy. Below $1 \%$ of them was with discolored body surface. Percent body crushes as a result of rough harvesting, handling and transportation was also reported to be below $1 \%$. Less than $1 \%$ prawn was received with excess water. They have also informed that, they did not receive any prawn with foreign materials (adulterate), dirt and mud. Due to the above quality defects they discarded around 1-2\% prawns last year. 
Table 8. Depot owners' opinion about the quality of Golda from their last year (2003) experiences

\begin{tabular}{lc}
\hline \multicolumn{1}{c|}{ Major Aspects } & Observation \\
\hline 1. \% spongy & $<1 \%$ \\
2. Discoloration & $<1 \%$ \\
3. \% body crushes & $<1 \%$ \\
4. \% with excess water & $<1 \%$ \\
5. \% with foreign materials (apparent) & $0 \%$ \\
6. \% with dirt and mud & $0 \%$ \\
7. \% discarded & $1-2 \%$ \\
\hline
\end{tabular}

\section{Overall impressions of the interviewers about the quality}

The interviewers themselves observed and noted some important aspects related to quality (Table 9). The points taken into consideration are- percent spongy, percent discoloration, percent body crushed, percent with excess water, percent with foreign materials, dirt and mud, percent not suitable for export, workers cleanliness and workers knowledge about quality and safe food and quality management. On the basis of the interviewers observations following quality defects are identified: less than $1 \%$ is spongy, below $1 \%$ with discolored body surface, about $1 \%$ with damaged crushed body due to rough handling and transportation, $1-2 \%$ with excess water, less than $1 \%$ with foreign materials and less than $1 \%$ with dirt and mud.

Due to above quality defects interviewers detected that about $1 \%$ prawn is not suitable for export. The overall cleanliness of the workers was not found satisfactory and most (about $(90 \%)$ of them have no knowledge about quality and post harvest quality management at Golda depots of sampling areas. Thus, most of the depots are with poor hygienic condition (Table 9).

The Condition of the Golda farms in terms of infrastructure facilities, overall management, harvesting methods, farm production system, post-harvest care, transportation and quality aspects are not satisfactory. Mazid, et al., (2001) studied the production, processing, transportation and handling of shrimps at the farm level and reported that the overall management procedures of the farms in respect of drying the pond bottom, ploughing, liming, fertilization, feeding, post-harvest handling, transportation and marketing system is very poor. They also studied different aspects and facilities of the depots and summarized following major problems: lack of landing facilities, infrastructure problems, lack of overall sanitation, inadequate toilet facilities, no office room and record keeping agreement, inadequate facility for storing the shrimp, no fly screen, dirty floor or earthen floor, inadequate drainage system, poor water quality and inadequate washing system, lack of quality consciousness etc. The present study also identified such types of problems responsible for the major quality loss in depots. 
Table 9. Interviewer's opinions

\begin{tabular}{llc}
\hline \multicolumn{1}{c|}{ Major Aspects } & Observation \\
\hline 1. $\%$ spongy & $<1 \%$ \\
2. \% discoloration & $<1 \%$ \\
3. \% body crushed & $1.0 \%$ \\
4. \% with excess water & $1-2 \%$ \\
5. \% with foreign materials & $<1 \%$ \\
6. \% with dirt and mud & $<1 \%$ \\
7. \% not exportable & $<1 \%$ \\
8. Workers cleanliness & $100 \%$ poor \\
9. Workers knowledge & $90 \%$ poor, $10 \%$ fair \\
10. Depots cleanliness & $90 \%$ poor, $10 \%$ fair \\
\hline
\end{tabular}

Organoleptically the shelflife of marine tiger shrimp (P. monodon) was found acceptable for processing for 8-9 days in ice storage and freshwater prawn (M. rosenbergii) acceptable for 5-6 days under similar storage conditions (Rahman et al., 2000; Kamal el al., 2000). The delayed icing of shrimp and prawn significantly reduces the shelf life (Rahman et al., 2001b; Rahman et al., 2001c).

Confirmation of safety and identification of potential problems were obtained by endproduct testing. Inspectors checked for compliance with the codes and sampled the foods for laboratory analysis. Although these actions are still essential parts of any foods control programme, they have certain limitations and thus, modern concept of quality depends on the overall quality management system from harvesting to consumption. Detection of major sites of qualitative and quantitative quality losses of prawn out side the processing industry reserves great importance to control or reduce the overall quality losses before they occurs.

\section{REFERENCES}

Ahmed, N. 2001. Socio-economic aspects of freshwater prawn culture development in Bangladesh. Ph.D thesis, 320 p. University of Starling, UK.

Angell, C. L. 1992. Inland freshwater prawn hateheries: introducing a new technology in Bangladesh. Bay of Bengal News, 48: 15-18.

DIFTA, 1993. Subsector study on the freshwater prawn Macrobrachium rosenbergii in Bangladesh. Danish Institute for Fisheries Technology and Aquaculture and Aquaculture (DIFTA), Histshals, Denmark.

DoF, 2005. Brief on Department of Fisheries Bangladesh, Department of Fisheries (DoF), Ministry of Fisheries and Livestock, Dhaka, Bangladesh.

Kamal, M., Rahman, M. M., Yasmin, L., Ahmed, S. U. and Islam, M. N. 2000. Studies on the postmortem changes in shrimp and prawn during ice storage: II. Biochemical aspects of quality changes. Bangladesh J. Fish. Res., 4(1): 91-96. 
Mazid, M. A., Ahmed, S. U., Kamal, M. and Islam, M. N. 2001. Studies on the improved production, processing, transport and handling of shrimps and their cost benefits at farm levels. Bangladesh Fisheries Research Institute and Department of Fisheries Technology, Bangladesh Agricultural University, Mymensingh. Completion Report., 147 p.

Rahman M. M., Yasmin, L., Nurullah, M., Kamal, M. and Islam, M. N. 2000. Studies on the postmortem changes in shrimp and prawn during ice storage: I. Organoleptic and physical changes. Bangladesh J. Fish. Res., 4(1): 83-89.

Rahman, M., Yasmin, L., Kamal, M., Mazid, M. A. and Islam, M. N. 2001a. Effect of delayed icing on the quality changes in brackish water shrimp Penaeus monodon during ice storage. Pak. J. Biologl. Sci., 4(11): 1390-1394.

Rahman, M, Yasmin, L., Kamal, M., Islam, M. N. and Ochiai, Y. 2001b. Quality changes in freshwater prawn Machrobrachium rosenbergii during ice storage. Bull. Fac. Edu. Ibaraki Univ. (Nat. Sci.) 50(2001): 39-49.

Rahman, M, Yasmin, L., Kamal, M., Kamruzzaman, M., Islam, M. N. and Ochiai, Y. 2001c. Effect of delayed icing on the quality changes in freshwater prawn Machrobrachium rosenbergii during subsequent storage. Bull. Fac. Edu. Ibaraki Univ. (Nat. Sci.) 50(2001): 51-57. 